\title{
Spatial Patterns and Spread of Potato Zebra Chip Disease in the Texas Panhandle
}

\author{
D. C. Henne, Texas AgriLife Research, Weslaco, TX; and F. Workneh and C. M. Rush, Texas AgriLife Research, Bushland, TX 79012
}

\begin{abstract}
Henne, D. C., Workneh, F., and Rush, C. M. 2012. Spatial patterns and spread of potato zebra chip disease in the Texas Panhandle. Plant Dis. 96:948-956

Zebra chip (ZC) is a disease that is affecting potato production in the southwestern United States and in other countries, and which has been linked to potato psyllids (Bactericera cockerelli) that harbor the bacterial plant pathogen 'Candidatus Liberibacter solanacearum'. Until recently, the epidemiology of $\mathrm{ZC}$ was unknown, motivating research to elucidate the spatial and temporal patterns of $\mathrm{ZC}$ infections in potato fields. Studies were performed in multiple commercial potato fields located in the Texas Panhandle, wherein locations of ZC-affected potato plants were georeferenced or counted within large plots and along belt transects consisting of contiguous 10-by-10-m quadrats. By employing distance- and area-based spatial statistical methods, it was determined that locations of ZC infections in potato fields departed from a completely spatially random pattern, instead appearing as clus-

ters comprising infected plants situated in close proximity to one another, with clusters interspersed with numerous solitary infections. Disease progress curves of $\mathrm{ZC}$ clusters were generally well described by exponential growth and quadratic polynomial models. Numbers of ZC infections within disease clusters gradually increased over multiple weeks, with foliar disease symptoms first appearing during the tuber bulking stage. ZC infections were not found to be continuously present across fields, because many quadrats along belt transects contained zero or only a few infections while others had numerous infections. Consequently, the frequency of ZC infections within belt transect quadrats was well described by negative binomial and zero-inflated negative binomial distributions, in agreement with observed clustering of infections and distance-based spatial statistical results.
\end{abstract}

An emerging disease of potato (Solanum tuberosum L.), predominantly known as "Zebra chip" (ZC) has been reported from the southwestern United States, as well as Mexico, Guatemala, Honduras, and New Zealand (12,16). Affected plants exhibit a broad range of symptoms that typically include leaf curling, leaf chlorosis, leaf scorching, swollen internodes, axillary bud and aerial tuber proliferation, necrosis of vascular system, and premature death. The name "Zebra chip" alludes to the brownish discoloration present in the vascular ring and medullary ray tissues within affected tubers, which is enhanced when tubers from chipping varieties are sliced and fried.

Although it was the chipping potato varieties in south Texas that were initially affected, it is now commonly known that all classes of potato are susceptible. Ever since it was first detected in Texas in 2000, ZC has been causing extensive losses to growers and processors in the United States. By the mid 2000s, several commercial potato producers in Texas suffered such a high incidence of $\mathrm{ZC}$ that entire fields were abandoned (16) and, because of chronically high ZC incidence, potato producers now subsequently avoid some areas of West Texas. However, during this time, neither the etiology of the disease nor involvement of a vector was known.

Recent studies $(4,7,11-13,21,23)$ have identified the putative pathogen associated with $\mathrm{ZC}$ as being the fastidious $\alpha$-proteobacterium 'Candidatus Liberibacter solanacearum' (syn. 'Ca. L. psyllaurous'), vectored by the potato psyllid, Bactericera cockerelli (Šulc) (Hemiptera: Triozidae), which was also previously determined to be associated with ZC $(16,17)$. Although Koch's postulates have not been fulfilled, laboratory $B$. cockerelli colonies that test positive for ' $\mathrm{Ca}$. L. solanacearum' using conventional or realtime polymerase chain reaction methods (23) routinely induce ZC

Corresponding author: D. C. Henne, E-mail: dchenne@ ag.tamu.edu

Accepted for publication 3 February 2012.

http://dx.doi.org/10.1094/PDIS-09-11-0805-RE

() 2012 The American Phytopathological Society symptoms in tubers and ultimately kill the host plant, whereas colonies that test negative do not.

Because $\mathrm{ZC}$ is a relatively new disease, there is a paucity of information concerning its epidemiology in potato fields. An analysis of the spatial patterns of ZC within potato fields could contribute to the elucidation of its epidemiology, which may lead to the development of an effective management strategy. Knowledge of the spatial patterns of plant diseases is a critical step toward understanding underlying vector-pathogen interactions that lead to plant disease epidemics. In nearly every epidemiological study, an evaluation of disease incidence or intensity is essential to properly assess treatment effects, quantify spatial-temporal patterns, evaluate crop losses, and formulate efficient sampling plans (14). This is especially important because new and recurring diseases caused by vector-borne plant pathogens have increased considerably in recent years (1). Therefore, the primary objective of this study was to use several spatial statistical approaches to characterize the spatial and temporal pattern of ZC-affected potato plants in multiple commercial potato fields in the Texas Panhandle.

\section{Materials and Methods}

Spatial point pattern of ZC. In 2008 and 2009, spatial patterns of $\mathrm{ZC}$ infections were assessed by employing distance-based (i.e., spatial point pattern analysis) and area-based (i.e., ZC frequency within quadrats) procedures (6) within commercial potato fields located in Lamb County, near Olton, TX. Potato crops in this region are typically grown in large (often nearly 50 ha or more) center-pivot irrigated fields. Because potato is a high-value crop, growers frequently apply insecticides to manage $B$. cockerelli populations. Therefore, it was not possible to perform these studies in unsprayed commercial potato fields. In all fields, insecticide regimens for control of $B$. cockerelli were uniformly applied in all regions in a manner similar to that described by Zens et al. (25). Briefly, growers applied a neonicotinoid at planting, followed by various rotations of insecticides in IRAC groups 6, 9, and 23 that are applied every 7 to 10 days. An important consideration is that potato growers in this region rotate the locations where they grow their potato crops and, typically, do not plant another potato crop on the same location within 3 years. Furthermore, grower prefer- 
ences changed from year to year, with the result that slightly different cultivars may have been planted. However, these cultivars were very similar, with most being "chipping" varieties. Additionally, Henne et al. (8) did not find significant differences in B. cockerelli movement behavior in potato fields that were planted to different chipping cultivars. Therefore, the study reported here presents a realistic picture of the situation found with spatial patterns of potato ZC under commercially grown processes.

The 2008 study was performed in a field planted to 'Russett Norkotah' (a non-chipping variety, planted mid-March). In the third week of June, ZC-symptomatic plants within a 4-ha area were systematically located and marked with wire stake flags. In all studies described from here on, tubers were excavated from all marked plants at the termination of field studies to verify ZC infections. Aboveground foliar symptoms of ZC are remarkably similar to other potato diseases, such as psyllid yellows (22) and many phytoplasmas (10). This presents a challenge when attempting to correctly identify ZC infections when multiple diseases are present within the same field. Excavating and examining tubers to determine whether ZC discoloration is present helps alleviate this problem and, in the vast majority of cases, provides a correct, fieldbased identification. Although this presents an added step to field identification of ZC, no alternative field-based diagnostic methods are currently available to positively identify potato plants that are infected with ' $\mathrm{Ca}$. L. solanacearum'. A second assessment was conducted in the first week of July to locate and mark newly symptomatic plants that had developed after the first assessment. All ZC-affected potato plants were georeferenced with a Trimble Geo XT handheld GPS receiver (Trimble Navigation Limited, Sunnyvale, CA) and disease intensity data from both assessment periods were merged for analysis (see Analysis section below).

The 2009 spatial pattern study was conducted in a potato field located approximately $3 \mathrm{~km}$ east of the field used for the 2008 study. This field was planted to the chipping 'FL 1867' potato (Russett Norkotah was not grown in this area during 2009 as it had been the previous year) in the third week of March and ZC intensity assessments were conducted within a single 1-ha area near the southern edge of the field on 17 June. A smaller area in 2009 was chosen not only because of time constraints but also because a 1-ha area was deemed adequate for characterizing ZC infection patterns, based on numerous field surveys throughout the Texas Panhandle. A second assessment was performed in the first week of July and all positively identified ZC-affected plants were georeferenced and the data merged as above for analysis.

ZC frequency assessments along belt transects. In 2008, belt transects were established in a commercial potato field (FL 1867, planted in mid-May 2008) located in Hartley County southeast of Dalhart, TX. The transects consisted of contiguous 10-by-10-m plots deployed from one edge of the field to the other edge, in both south-north and east-west directions ( $n=77$ to 85 plots/transect). To obtain information about disease progress and infection frequencies, assessments were performed weekly for five consecutive weeks, beginning the third week of August (when the first plants exhibiting ZC-like symptoms were detected) until October 2008.

In 2009, a similar study was conducted in Lamb County, TX in the same field used for the spatial point pattern assessment (see above). Belt transects were established as above (in 2008 studies) and, in the middle of July, all ZC infections within quadrats were marked with a wire stake flag and counted. In this field, ZC intensity assessments were conducted only once, a few days prior to harvest.

Evolution of ZC clusters and disease progression. In the 2008 belt transect study described above, the opportunity was presented to evaluate evolution of $\mathrm{ZC}$ infection clusters. Detailed studies were performed on several disease clusters, whereby newly formed symptomatic plants were marked with different colored wire stake flags corresponding to the different weekly observations, and the positions of all the different colored flags georeferenced just prior to harvest. Additional disease cluster evolution assessments were conducted in 2009 in a commercial potato field near Dalhart, TX. One of several ZC clusters in a field planted to FL 1867 was moni- tored for 5 weeks, beginning when the first $\mathrm{ZC}$ infections were observed (24). Individual infected plants were marked weekly with colored wire stake flags as above and georeferenced just prior to harvest.

Analyses. Georeferenced locations of ZC infections (i.e., "events") in the spatial point pattern surveys were analyzed using basic distance-based approaches to identify departures from complete spatial randomness (CSR). To be considered completely spatially random, three requirements must be met: invariance in the number of points per unit area (i.e., intensity) within the study area, independent distribution of points, and no interaction among points (e.g., inhibition) $(5,6,9)$.

Georeferenced locations of ZC infections were analyzed by examining first- and second-order properties to describe the spatial point pattern $(5,6,9)$. Briefly, first-order properties of a stochastic spatial point process (assumed to be constant over the entire region) describe, through a kernel estimation process, how the mean number of points per unit area (i.e., intensity) varies through space (6). Local estimates at given points in a region are weighted as a sum of the points in its neighborhood (region of influence). The weighted sum is derived from a bivariate polynomial density function (kernel). From this procedure, ZC intensity maps were generated showing the locations of $\mathrm{ZC}$ infections as well as the intensity of points where ZC-affected plants were located within the area sampled. These maps reveal whether the intensity of ZC is invariant over the sample space and identify areas where the number of events is greater than average.

Second-order properties describe the covariance (i.e., spatial dependence) between the values of the stochastic process at different spatial regions. For second-order analyses, origin-to-point and point-to-point nearest-neighbor statistics ( $\hat{F}$ and $\hat{G}$, respectively) were computed for each ZC spatial point pattern. Nearest-neighbor distances offer an objective means for examining small-scale interactions between points in the area of interest (9). Distances are measured from the $i$ th origin or point to the nearest other point in the area. Figures were generated to show the empirical distribution functions (EDFs) of the spatial point patterns. Visual examinations of EDFs are useful for identifying departures from CSR. For example, the EDF for $\hat{G}$ is calculated as follows:

$$
\hat{G}(y)=n^{-1} \sum_{d_{i} \leq y} 1
$$

where $n$ is the number of points in the area and $d_{i}$ is the nearestneighbor distance from the $i$ th point to the nearest other point in the area of interest (9). The origin-to-point nearest-neighbor statistic $\hat{F}$ is calculated similarly to $\hat{G}$, as follows:

$$
\hat{F}(x)=m^{-1} \sum_{e_{i} \leq x} 1
$$

where $m$ is the number of origins and $e_{i}$ is the distance from the $i$ th origin to the nearest of the $n$ points, except that interpretation of its EDF is different (see Results).

Because edge effects from interactions with unobserved events outside the study area need consideration, testing for CSR involves using Monte Carlo techniques to simulate an EDF of nearestneighbor distances obtained from the original point pattern (9). This EDF is derived from a modified Ripley's K-function (19) that incorporates a variance stabilizing transformation, $\hat{L}$ :

$$
\hat{L}(d)=\sqrt{\frac{K(d)}{\pi}}
$$

where

$$
K=n^{-2}|A| \sum \sum_{i \neq j} w_{i, j}^{-1} I_{d}\left(d_{i, j}\right)
$$

and where $n$ represents the number of points within region $A$ with area $|A|, d_{i, j}$ represents the distance between the $i$ th and $j$ th points, $w_{i, j}$ represents the proportion of the circle with its center at point $i$ and which passes through point $j$ lying within $A$, and $I_{d}\left(d_{i, j}\right)$ is an 
indicator function, equal to 1 if $d_{i, j} \leq d$ (9). These simulations produce a CSR reference line, and an envelope comprising the maximum and minimum. An EDF that lies outside of the simulation envelope is further evidence of departure from CSR. Here, first- and second-order properties of observed ZC spatial point patterns were analyzed using the spatial statistics program $\mathrm{S}+$ (version 8.2; Tibco Software Inc., Palo Alto, CA).

Plots were generated in Microsoft Excel (2010 version 14.1.4) to illustrate ZC intensity along the contiguous 10 -by-10-m belt transect quadrats. The numbers of $\mathrm{ZC}$ infections within quadrats along north-south, east-west, and pooled transects were used to create ZC frequency distributions using PROC FREQ in SAS 9.2 (20). As is typically the case with a clustered spatial process, the data were found to contain many zero values, and observed ZC frequency distributions were tested against Poisson, zero-inflated Poisson, negative binomial, and zero-inflated negative binomial distributions using the PROC COUNTREG procedure in SAS 9.2. Model performance was evaluated using Akaike's Information Criterion (AIC). The AIC is a method based on information theory that enables model selection based on which model is a likely candidate, and quantifies how much more likely it is to be the correct model (15). When comparing models, the model with the lower score is likely the correct one but AIC does not explicitly reject other models nor deem one significantly better than the other. Here, AIC was computed based the following equation:

$$
A I C=n \cdot \ln \left(\frac{S S E}{n}\right)+2 p
$$

where $n$ is the number of observations, SSE is sum of squared errors, and $p$ is the number of parameters included in the model.
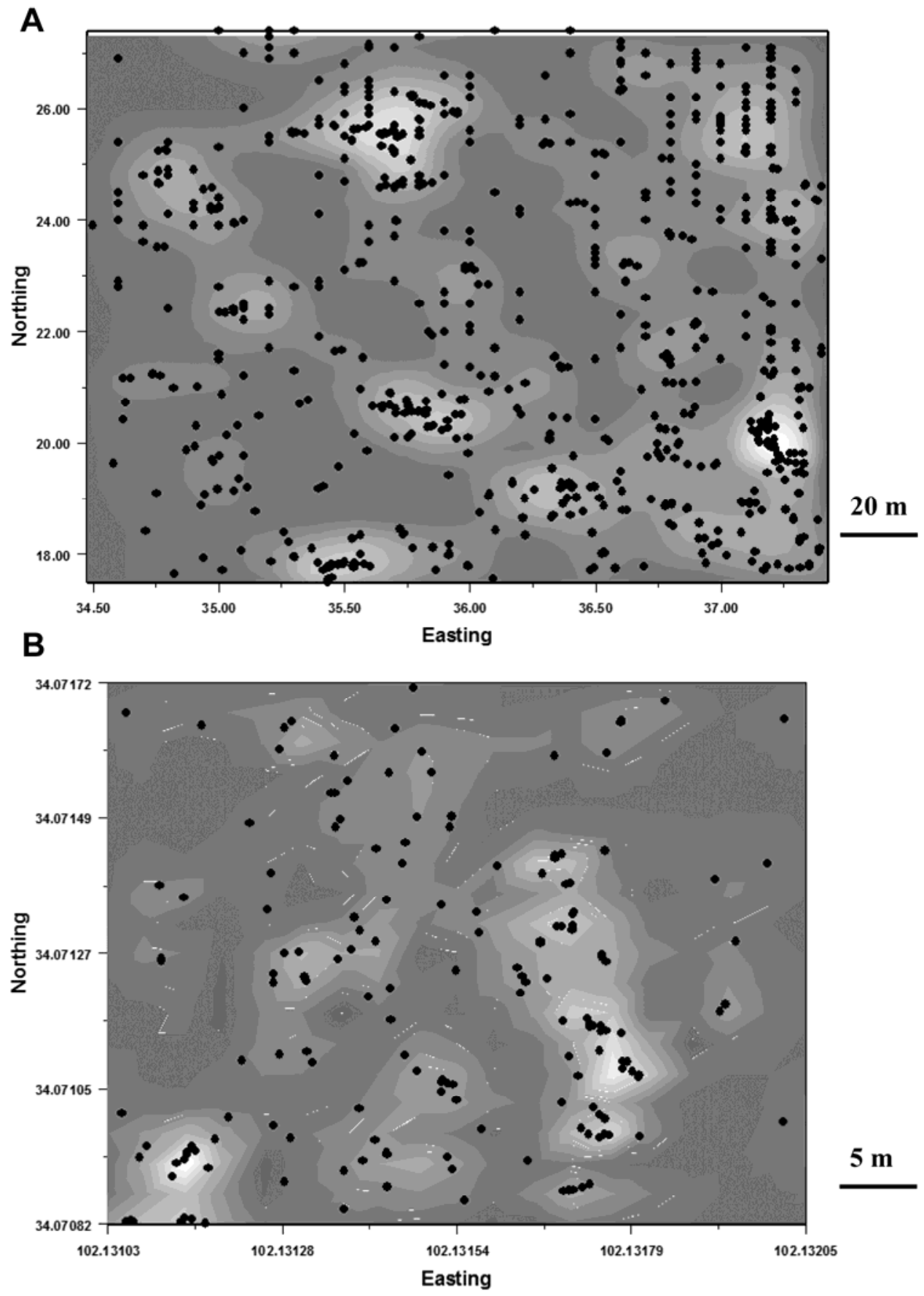

Fig. 1. Spatial point patterns overlaid with intensity maps representing georeferenced locations of Zebra chip $(\mathrm{ZC})$ infections within commercial potato fields located at $A$, Olton, TX (2008) and B, Olton, TX (2009). Lighter shading represents areas of the sampled area where ZC intensity was greater than average. 
Finally, figures were generated in Excel to illustrate the cluster evolution and associated disease progress curves. Curves were fitted to accumulated disease over time using Prism 5.03 (GraphPad Software, Inc., La Jolla, CA) using either quadratic polynomial or exponential models.

\section{Results}

Spatial point pattern of ZC. In the 2008 spatial pattern survey, 705 ZC-symptomatic plants were identified and georeferenced within the 4-ha study area situated within a commercial potato field at Olton, TX. In the 2009 spatial pattern survey, 162 infected plants within the 1-ha study area were similarly identified and georeferenced. Mapped spatial-point patterns for the two yearly ZC intensity assessments are shown in Figure 1A and B. In both maps, clustering of points interspersed with solitary points is evident, suggesting a non-CSR pattern of $\mathrm{ZC}$ infections. With the spatial point intensity maps obtained from the kernel estimation procedure overlaid on top of the locations of $\mathrm{ZC}$ infections (Fig. $1 \mathrm{~A}$ and $\mathrm{B})$, regions where $\mathrm{ZC}$ infection intensity is greater than average appear as patches of lighter shading. The EDFs of the 2008 and 2009 Olton spatial point patterns (Fig. 2A and C, and B and D, respectively) also imply departures from CSR: the presence of an
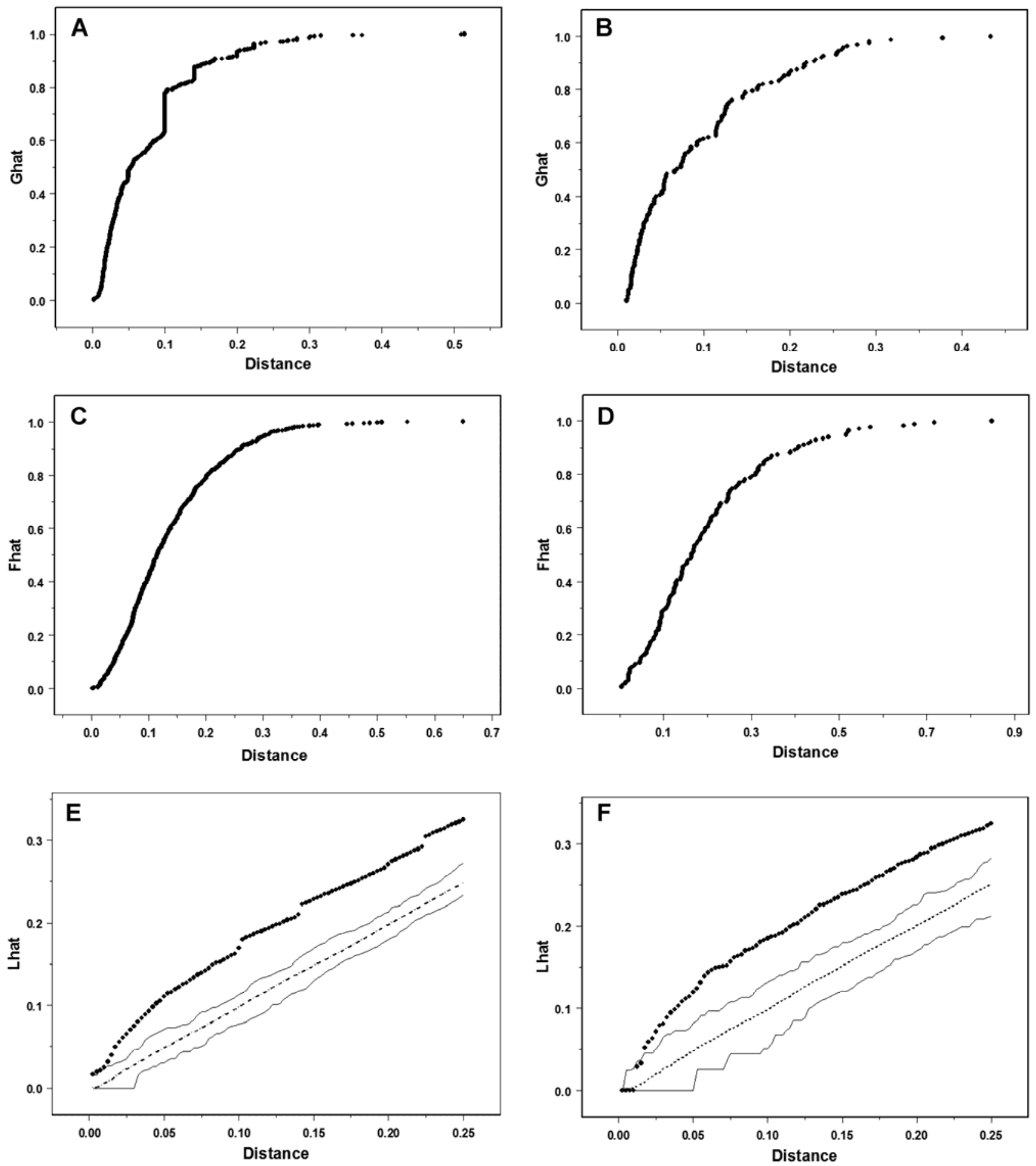

Fig. 2. Empirical distribution functions of georeferenced locations of Zebra chip (ZC) infections described in Figure 1, A, $\hat{G}$ (G-hat) (Olton, TX 2008); B, $\hat{G}$ (Olton, TX 2009); C, $\hat{F}$ (F-hat) (Olton, TX 2008, D, $\hat{F}$ (Olton, TX 2009); E, $\hat{L}$ (L-hat) (Olton, TX 2008); and F, $\hat{L}$ (Olton, TX 2009). Refer to text for explanations of $\hat{G}, \hat{F}$, and $\hat{L}$. 
excess of short-distance values in $\hat{G}$ (Fig. $2 \mathrm{~A}$ and B) indicates spatial clustering, as does the presence of an excess of highdistance values in $\hat{F}$ (Fig. $2 \mathrm{C}$ and D). In both years, the number of $\mathrm{ZC}$ infections had increased between the first and second assessments. The departure from CSR is further proven by the $\hat{L}$ EDFs for both spatial point patterns (Fig. 2E and F), which show that the EDFs representing the observed point patterns for both locations lie well outside of the CSR simulation envelope obtained from the Monte Carlo procedure.

ZC frequency assessments along belt transects. Frequency distributions of ZC intensity within the contiguous 10-by-10-m quadrats are shown in Figure $3 \mathrm{~A}$ and $\mathrm{B}$. On average, $50 \%$ of the quadrats contained no ZC-symptomatic plants. Most quadrats contained $<2$ infections, but some had $>15$. Based on AIC values, the observed ZC frequency distributions (north-south, east-west, and pooled) were fit better with negative binomial and zero-inflated negative binomial distributions than with Poisson and the zeroinflated Poisson distributions (Table 1). Patterns of ZC counts along the belt transects in the 2008 study in Dalhart depended on axis orientation. The north-to-south transect yielded a repeating pattern of increased ZC intensity approximately every $60 \mathrm{~m}$ (Fig. 4A). The east-to-west belt transect had no distinct pattern, except for a higher intensity of ZC infections along the eastern edge (Fig. 4B) that was attributed to immigration of B. cockerelli from an
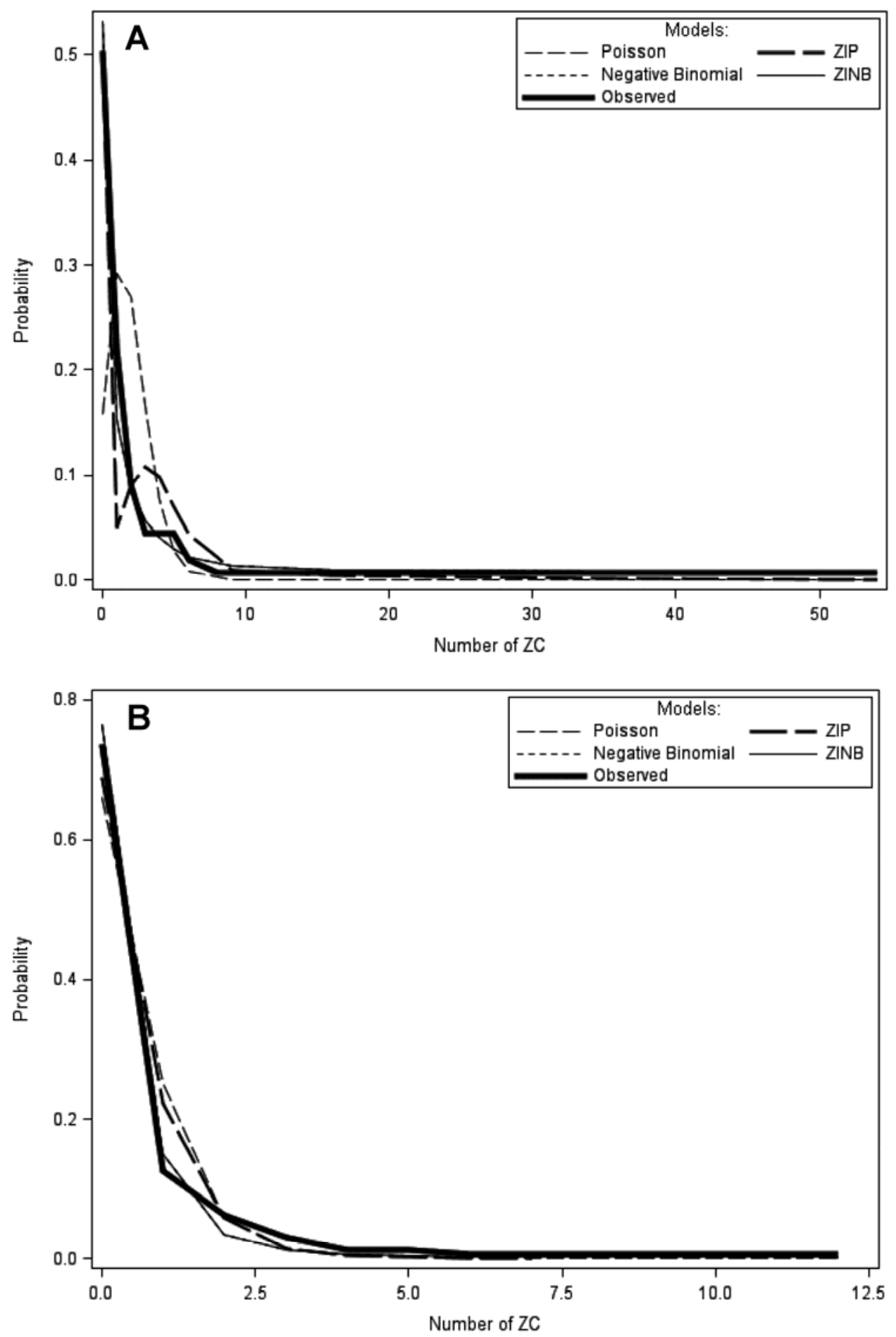

Fig. 3. Observed and expected frequency distributions of Zebra chip (ZC) infections within 10-by-10-m belt transect quadrats: A, Dalhart, TX (2008) and B, Olton, TX (2009). Data were pooled from two transects at each location. 
earlier harvested potato field located $<50 \mathrm{~m}$ to the east. The 2009 Olton belt transects had no obvious pattern in either direction (Fig. $4 \mathrm{C}$ and $\mathrm{D}$ ), except for the presence of more $\mathrm{ZC}$ infections on the southern and western halves of the south-to-north and east-to-west transects, respectively. The distribution of $\mathrm{ZC}$ along these transects was patchy, often with many consecutive empty quadrats interspersed between quadrats containing variable numbers of $\mathrm{ZC}$-affected plants.

Evolution of ZC clusters and disease progression. Clusters of ZC-affected plants within potato fields slowly evolved over time, with individual clusters eventually being 5 to $10 \mathrm{~m}$ in diameter (Fig. 5A [5 m] and $\mathrm{C}$ and $\mathrm{E}[10 \mathrm{~m}]$ ). The cumulative number of $\mathrm{ZC}$ infections within these disease clusters gradually increased over time, and locations of new infections generally appeared in close proximity to one another (Fig. 5A-F). Disease progress curves for the two Dalhart (2008) ZC clusters (Fig. 5B and D) were fit well by an exponential growth model (Fig. 5B, $Y=0.1992 e^{(0.9557 X)}\left[R^{2}=\right.$ $0.99]$ and $\left.\mathrm{D}, Y=0.1752 e^{(0.6032 X)}\left[R^{2}=0.98\right]\right)$, while the Dalhart (2009) disease progress curve was fit by a quadratic polynomial (Fig. 5F, $Y=-4.6+5.029 X-0.2857 X^{2}\left[R^{2}=0.99\right]$ ). Furthermore, these disease clusters were isolated from other disease clusters within the same field (Fig. 1). In two of the clusters (Fig. 5B and D), the number of new symptomatic plants observed increased over time, while the third exhibited a declining trend (Fig. 5F).

Table 1. Comparison of discrete frequency distributions using Akaike's Information Criterion to model observed frequencies of Zebra chip (ZC) infections within 10-by-10-m belt transect quadrats ${ }^{\mathrm{a}}$

\begin{tabular}{|c|c|c|c|c|c|c|}
\hline$\overline{\text { Year }}$ & Location & Direction & Poisson & ZIP & Negative binomial & ZINB \\
\hline \multirow[t]{3}{*}{2008} & Dalhart & North-south & 450.6 & 379.9 & 270.1 & 272.1 \\
\hline & $\ldots$ & East-west & 593.9 & 477.0 & 270.0 & 272.0 \\
\hline & & Pooled & 1,042 & 854.9 & 535.2 & 537.2 \\
\hline \multirow[t]{3}{*}{2009} & Olton & North-south & 211.5 & 174.7 & 169.5 & 171.3 \\
\hline & $\ldots$ & East-west & 221.7 & 174.6 & 158.9 & 160.9 \\
\hline & $\ldots$ & Pooled & 429.9 & 353.2 & 322.75 & 324.8 \\
\hline
\end{tabular}

${ }^{a}$ ZIP = zero-inflated Poisson and ZINB = zero inflated negative binomial. Smaller numbers correspond with a better-fitting model.
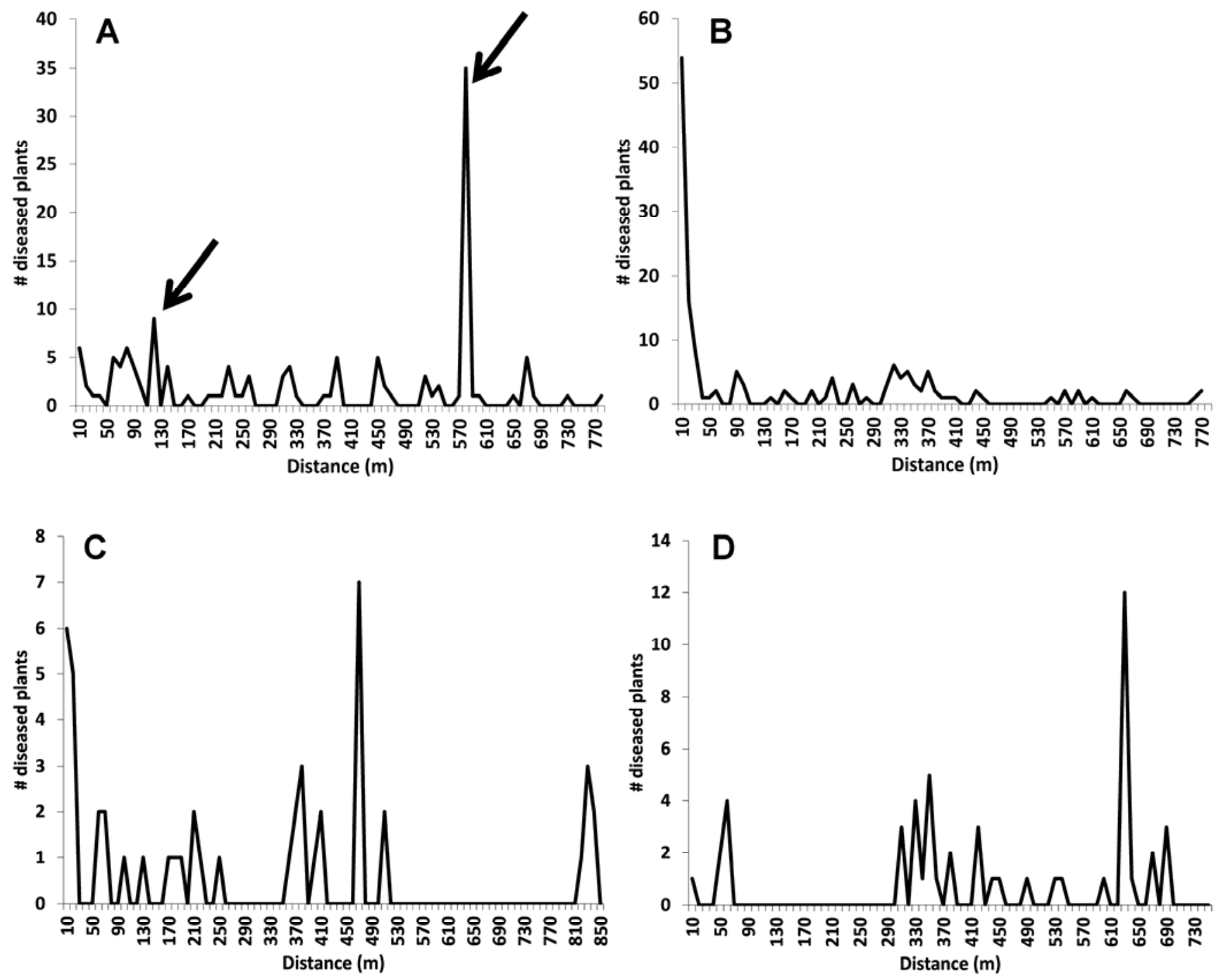

Fig. 4. Intensity of Zebra chip (ZC) infections within contiguous 10-by-10-m quadrat belt transects. Transects were deployed from field edge to field edge in two cardinal directions: A, Dalhart, TX south-to-north transect; B, Dalhart, TX east-to-west transect; C, Olton, TX south-to-north transect; and D, Olton, TX east-to-west transect. Arrows in A indicate locations of clusters shown in Figure $5 \mathrm{~A}$ and $\mathrm{C}$. 
This dissimilarity in pattern of new ZC development over time may be attributed to differences in time of observations, because the third cluster (July to August 2009) was observed at a different time from the other two (August to September 2008). Generally, plants within a disease cluster will have disease symptoms ranging from mild to severe, with plants in the early phase of disease expression having mild ZC symptoms that later become severe.
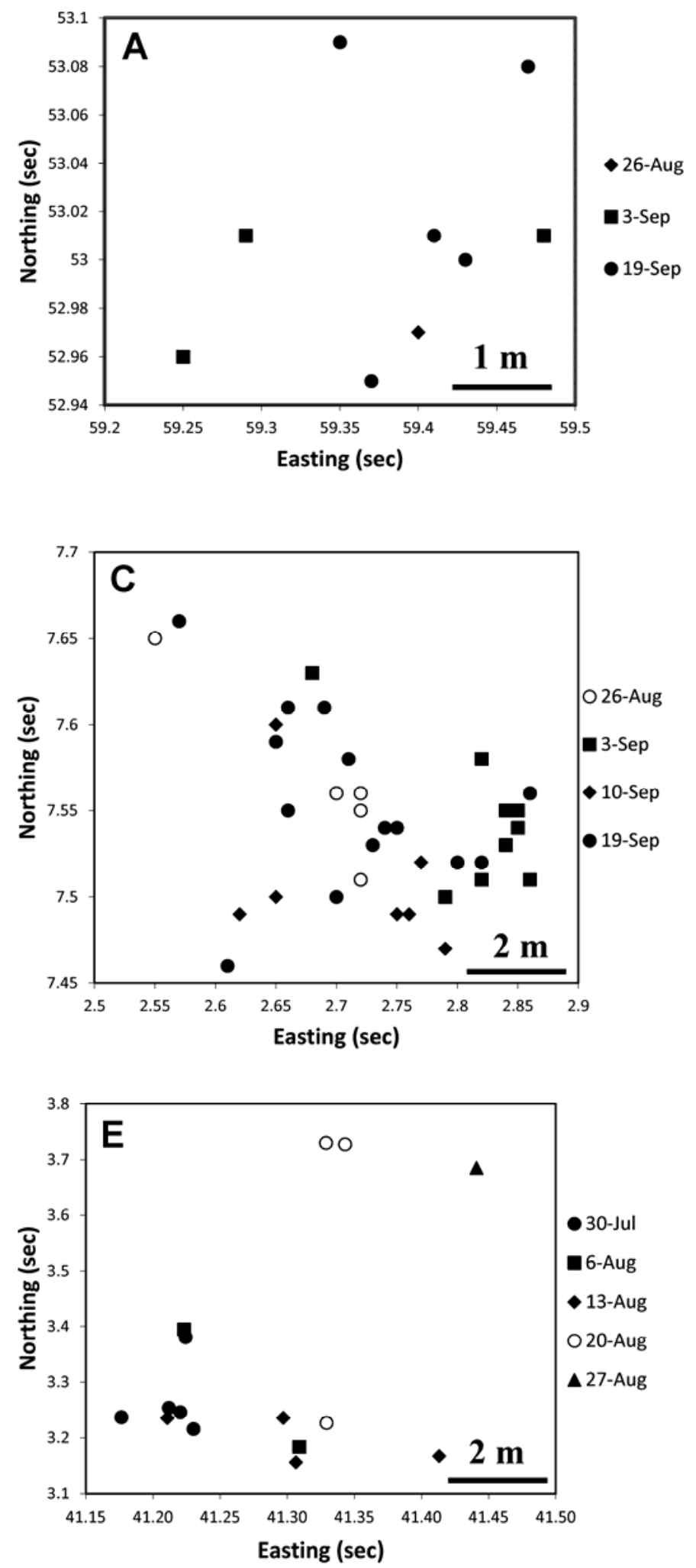

\section{Discussion}

Results of field studies were presented to elucidate spatial patterns of ZC within potato fields located in the Texas Panhandle. Analyses of ZC intensity using distance-based and area-based methods confirmed our earlier observations that clusters of diseased plants gradually evolved within potato fields. Explanations for the gradual increase in new infections are not known at this
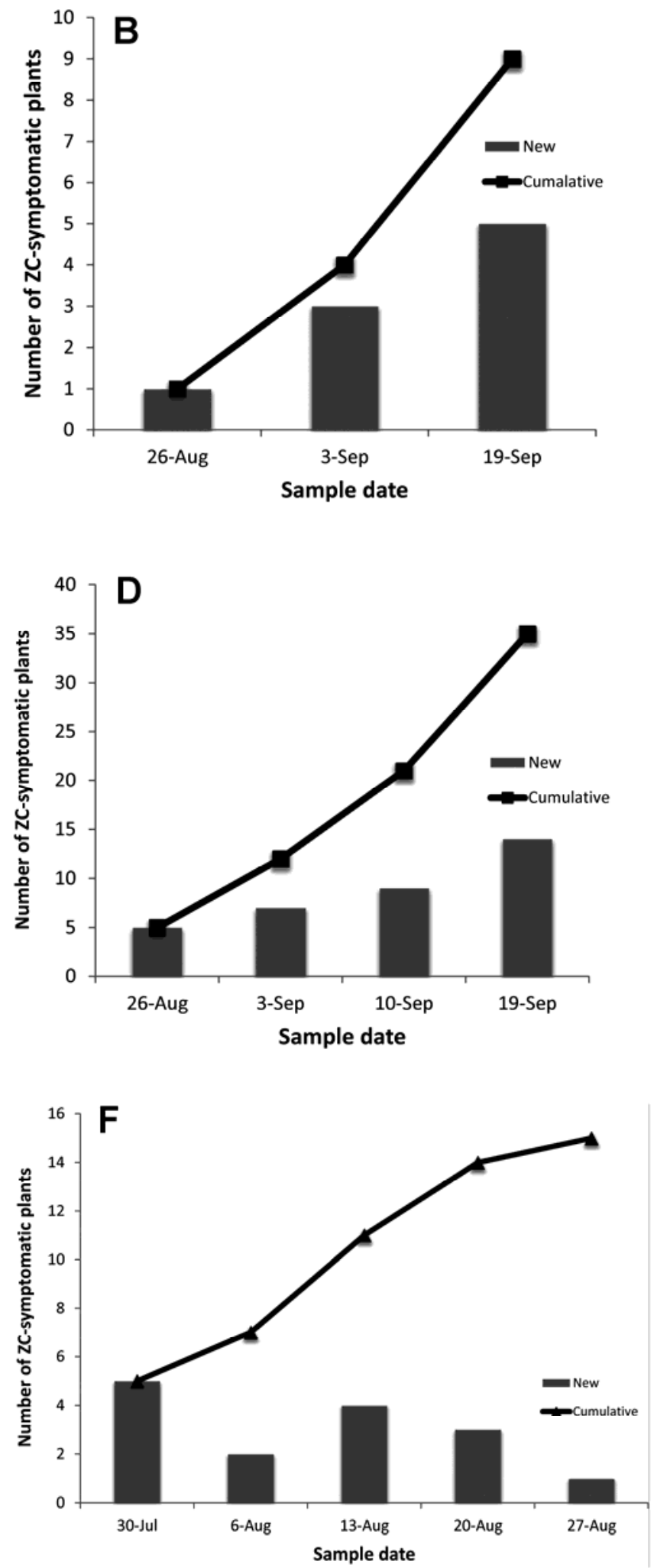

Fig. 5. Zebra chip (ZC) cluster evolution over time from weekly assessments: A-D, Dalhart, TX (2008); E and F, Dalhart, TX (2009). 
time; however, this evolving pattern could result from individual bacterialiferous psyllids infecting multiple plants with ' $\mathrm{Ca}$. L. solanacearum' within a localized area over time, eventually resulting in the evolution of diseased plant clusters. Alternatively, multiple bacterialiferous psyllids may have landed in the same area over an extended time or there may have been secondary spread of bacterialiferous female F1 progeny. Whatever the process of formation, disease clusters were more or less isolated from other such clusters within fields, indicating that a local process was involved.

Expression of foliar symptoms of ZC did not typically occur until potato growth stage III and IV (i.e., after tuber bulking). In potato fields, plants with ZC symptoms began to appear at 66 to 75 days after planting (after the bloom period had elapsed) and continued to increase thereafter. Additional information on ZC disease progress curves and edge effects (i.e., increased ZC along field edges, not interactions from unobserved events from outside a bounded region of space) are presented in a study by Workneh et al. (24). However, it is important to note that there is normally a lag of 3 to 4 weeks, depending on environmental conditions and plant growth stage, between the beginning of psyllid feeding and expression of symptoms. Furthermore, because of the absence of symptoms in the field until after bloom, any attempts to relate ZC intensity to earlier vector densities and specific infection events is not straightforward.

Similar disease clustering patterns with insect-transmitted plant pathogens have been reported elsewhere. For instance, Camann et al. (2) reported significant spatial aggregation of peanut plants infected by Tomato spotted wilt virus within peanut fields, although the aggregated plants themselves occurred more or less randomly as clusters of infected plants. They suggested that these clusters were the result of primary infection from viruliferous thrips that redispersed short distances after arriving in the field. Although the clustering of ZC infections in potato fields would suggest secondary spread of bacterialiferous vectors from a focal plant, as described above, our observations of cluster evolution suggest primary spread to be more likely; however, at least some secondary spread cannot be ruled out.

A primary type of disease spread obscures efforts to correlate vector abundance to disease intensity, especially if the relationship between vector abundance and vector movement is not clearly understood (18). Recently, it was found that B. cockerelli adults were capable of moving substantial distances within potato fields (8) but density-dependent movement patterns were not evaluated. A range of biotic and abiotic factors that function at various scales (from small-scale interaction of a plant pathogen with individual host plants to large-scale ecological processes) will influence spatial patterns of infected plants, thereby affecting dispersal and hostselection behavior of arthropod vectors (2). In the present study, two to four consecutive ZC infections were occasionally found along the same row, suggesting that a solitary bacterialiferous vector was traveling from plant to adjacent plant along a row. On a larger scale, there were instances where certain potato fields had moderate to heavy intensity of ZC while other fields in the same area had no ZC or only a low intensity of ZC. The reasons for this disparity among fields are not clear but may be attributed to differences in planting dates, different cultivars, and consequent attractiveness to migrating B. cockerelli. Similar ZC patterns and spread were found in most fields, regardless of location or cultivar.

The presence of increased ZC intensity approximately every 60 $\mathrm{m}$ along the south-north Olton 2008 belt transect is difficult to interpret. The ZC intensity studies described here were performed within intensively managed potato fields and it is not known if the multiple insecticide applications normally applied throughout the growing season affected $B$. cockerelli movement and subsequent disease intensity, patterns, and progression. In the absence of insecticide applications. disease incidence would have been considerably higher (25). The presence of higher disease intensity along the southern and western halves of the Olton 2009 transects does suggest that bacterialiferous $B$. cockerelli had migrated into that field from the west and south. Similar observations have been made in other fields in this same area (unpublished data), and a greater abundance of $B$. cockerelli adults has been reported along southern edges of potato fields in Colorado (3).

Plant disease frequency counts can be fit by a number of different discrete probability distributions (14). Because counts of diseased plants are considered to be a binary variable (i.e., diseased or not diseased), the appropriate description of disease intensity would appear to follow a binomial or $\beta$-binomial distribution. The exception to this would be in cases where means are low or mean incidence is 0.20 or less (as in the study reported here), in which case they can be adequately approximated by other count distributions (14). The ZC intensity data in this study was better fit by a negative binomial distribution, which corresponds with the largely aggregated pattern of this disease in potato fields. However, when our studies were performed, the intensity of ZC infections was much lower than was observed in previous years (often $<5 \%$ of plants were infected). Whether this represented an actual downturn in disease pressure or was the result of improved potato psyllid management practices is not currently known. Other frequency distributions may better describe instances where $\mathrm{ZC}$ infections are much more widespread.

The ZC studies reported here are an important step toward understanding this disease-vector pathosystem and finding ways to mitigate disease intensity. Although not quantified to the extent of these Texas Panhandle studies, we observed similar spatial patterns of ZC in potato fields located in other regions of the United States where ZC has been reported (south Texas, Kansas, and Nebraska). Current research is addressing ZC infection patterns in potato fields located in other countries and whether ZC infection patterns vary among different potato cultivars or are different in tomato and pepper crops. These studies will accumulate data, which should be useful in development of ZC disease-progression and risk-assessment models.

\section{Acknowledgments}

This research was supported by the Texas Department of Agriculture Zebra Chip Initiative and by ZC SCRI Award number 2009-51181-20178. We thank CSS Farms for their support of this project; J. Arthur, C. Childers, and B. Ketelle for technical assistance in the field and laboratory; and several anonymous reviewers for comments that greatly improved this manuscript.

\section{Literature Cited}

1. Almeida, R. P. P. 2008. Ecology of emerging vector-borne plant diseases. In: Institute of Medicine Forum on Vector-borne Diseases: Understanding the Environmental, Human Health, and Ecological Connections. National Academies Press, Washington, DC.

2. Camann, M. A., Culbreath, A. K., Pickering, J. W., and Demski, J. W. 1995. Spatial and temporal patterns of spotted wilt epidemics in peanut. Phytopathology 85:879-885.

3. Cranshaw, W. S. 1994. The potato (tomato) psyllid, Paratrioza cockerelli (Sulc), as a pest of potatoes. Pages 83-95 in: Advances in Potato Pest Biology and Management. G. W. Zehnder, M. L. Powelson, R. K. Hansson, and K. V. Raman eds. American Phytopathological Society, St. Paul, MN.

4. Crosslin, J. M., and Munyaneza, J. E. 2009. Evidence that the zebra chip disease and the putative causal agent can be maintained in potatoes by grafting and in vitro. Am. J. Pot. Res. 86:183-187.

5. Diggle, P. J. 2003. Statistical Analysis of Spatial Point Patterns, second edition. A Hodder Arnold Publication, London.

6. Gatrell, A. C., Bailey, T. C., Diggle, P. J., and Rowlington, B. S. 1996. Spatial point pattern analysis and its application in geographical epidemiology. Trans. Inst. Br. Geogr. 21:256-274.

7. Hansen, A. K., Trumble, J. T., Stouthamer, R., and Paine, T. D. 2008. A new Huanglongbing species, 'Candidatus Liberibacter psyllaurous', found to infect tomato and potato, is vectored by the psyllid Bactericera cockerelli (Sulc). Appl. Environ. Microbiol. 74:5862-5865.

8. Henne, D. C., Workneh, F., and Rush. C. M. 2010. Movement of Bactericera cockerelli (Heteroptera: Psyllidae) in relation to potato canopy structure, and effects on potato tuber weights. J. Econ. Entomol. 103:1524-1530.

9. Kaluzny, S. P., Vega, S. C., Cardoso, T. P., and Shelly, A. A. 1998. S+ Spatial Stats: User's Manual for Windows and UNIX. Springer, New York.

10. Lee, I.-M., Bottner, K. D., Secor, G., and Rivera-Varas, V. 2006. 'Candidatus Phytoplasma americanum', a phytoplasma associated with a potato purple top wilt disease complex. Int. J. Syst. Evol. Microbiol. 56:1593-1597.

11. Li, W, Abad, J. A., Fench-Monar, R. D., Rascoe, J., Wen, A., Gudmestad, N. C., Secor, G. A., Lee, I.-M., and Levy, L. 2009. Multiplex real-time PCR for detection, identification and quantification of 'Candidatus Liberibacter solanacearum' in potato plants with zebra chip. J. Microbiol. Methods 
78:59-65.

12. Liefting, L. W., Perez-Egusquiza, Z. C., and Clover, G. R. G. 2008. A new 'Candidatus Liberibacter' species in Solanum tuberosum in New Zealand. Plant Dis. 92:1474.

13. Liefting, L. W., Sutherland, P. W., Ward, L. I., Paice, K. L., Weir, B. S., and Clover, G. R. G. 2009. A new 'Candidatus Liberibacter' species associated with diseases of solanaceous crops. Plant Dis. 93:208-214.

14. Madden, L. V., and Hughes, G. 1995. Plant disease incidence: distributions, heterogeneity, and temporal analysis. Annu. Rev. Phytopathol. 33:529-564.

15. Motulsky, H., and Christopoulos, A. 2003. Fitting Models to Biological Data using Linear and Nonlinear Regression: A Practical Guide to Curve Fitting. Graphpad Software Inc., San Diego, CA.

16. Munyaneza, J. E., Crosslin, J. M., and Upton, J. E. 2007. Association of Bactericera cockerelli (Homoptera: Psyllidae) with "Zebra Chip", a new potato disease in Southwestern United States and Mexico. J. Econ. Entomol. 100:656-663.

17. Munyaneza, J. E., Goolsby, J. A. Crosslin, J. M., and Upton, J. E. 2007. Further evidence that zebra chip potato disease in the Lower Rio Grande Valley of Texas is associated with Bactericera cockerelli. Subtrop. Plant Sci. 59:30-37.

18. Raccah, B., and Irwin, M. E. 1988. Techniques for studying aphid-borne virus epidemiology. Pages 209-222 In: Experimental Techniques in Plant Disease Epidemiology. J. Kranz and J. Rotem eds. Springer-Verlag, Berlin.

19. Ripley, B. D. 1976. The second-order analysis of stationary point processes.
J. Appl. Prob. 13:255-266.

20. SAS Institute. 2008. SAS User's Guide: Statistics, version 9.2. SAS Institute, Cary, NC.

21. Secor, G. A., Rivera, V. V., Abad, J. A., Lee, I. M., Glover, G. R. G., Leifting, L. W., Li, X., and De Boer, S. H. 2009. Association of 'Candidatus Liberibacter solanacearum' with zebra chip disease of potato established by graft and psyllid transmission, electron microscopy, and PCR. Plant Dis. 93:574-583.

22. Sengoda, V. G., Munyaneza, J. E., Crosslin, J. M., Buchman, J. L., an Pappu, H. R. 2010. Phenotypic and etiological differences between psyllid yellows and zebra chip diseases of potato. Am. J. Pot. Res. 87:41-49.

23. Wen, A., Mallik, K., Pasche, J.S., Wang, X., Li, W., Levy, L., Lin, H., Alvarado, V. Y., Scholtof, H., Mirkov, E., Rush, C. M., and Gudmestad, N. C. 2009. Detection, distribution, and genetic variability of 'Candidatus Liberibacter' species associated with zebra complex disease of potato in North America. Plant Dis. 93:1102-1115.

24. Workneh, F., Henne, D. C., Childers, A. C., Paetzold, L., and Rush, C. M. 2012. Assessments of edge effect in intensity of potato zebra chip disease. Plant Dis. 96:943-947.

25. Zens, B., Rush, C. M., Henne, D. C., Workneh, F., Bynum, E., Nansen, C., and Gudmestad, N. C. 2010. Efficacy of seven chemical programs to control potato psyllids in the Texas panhandle. Pages 83-87 in: Proc. 10th Annu. Zebra Chip Rep. Session. F. Workneh and C. M. Rush, eds. Dallas, TX. 